\title{
Aristotle on the Purity of Forms in MetaphYSICS Z.10-11
}

\author{
SAMUEL MEISTER \\ Brown University
}

\begin{abstract}
Aristotle analyses a large range of objects as composites of matter and form. But how exactly should we understand the relation between the matter and form of a composite? Some commentators have argued that forms themselves are somehow material, that is, forms are impure. Others have denied that claim and argued for the purity of forms. In this paper, I develop a new purist interpretation of Metaphysics Z.10-11, a text central to the debate, which I call 'hierarchical purism'. I argue that hierarchical purism can overcome the difficulties faced by previous versions of purism as well as by impurism. Roughly, on hierarchical purism, each composite can be considered and defined in two different ways: From the perspective of metaphysics, composites are considered only insofar as they have forms and defined purely formally. From the perspective of physics, composites are considered insofar as they have forms and matter and defined with reference to both. Moreover, while the metaphysical definition is a definition in the strict sense of 'definition', the physical definition is a definition in a loose sense. Analogous points hold for intelligible composites and geometry. Finally, neither sort of definitional practice implies that, for Aristotle, forms are impure.
\end{abstract}

$\mathrm{I}$ N Metaphysics Z.11, Aristotle's investigation into substance culminates in the claim that form is primary substance. ${ }^{1}$ On the way, Aristotle develops an account of the relation between matter and form which has generated a great deal of exegetical controversy. Some scholars take Aristotle to argue that forms involve matter, that is, that forms are impure. By contrast, other commentators hold that, for Aristotle, forms do not involve matter, that is, forms are pure. The importance of the question cannot be overstated. For if forms involve matter,

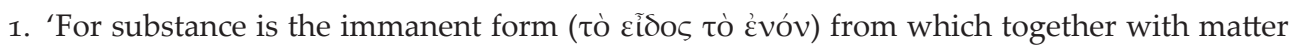
the composite substance is said' (1037a29-30).

Contact: Samuel Meister <meister.samuel@gmail.com> 
matter is part of the essence of form, and hence the explanatory priority of form over matter, and the status of forms as primary substances, is threatened (see Malink 2013: 245).

As I see it, the exegetical debate over the purity of forms has reached something of an impasse. As far as Z.11 is concerned, there has been an unfortunate tendency to focus on a few passages, most notably the so-called 'Socrates the Younger Passage' (1036b21-32), with little attention paid to their larger argumentative context. In order to advance the debate, a more contextual reading is required which considers the overall architectonic of the chapter as well as the way in which it builds on the preceding Z.10. In the following, then, I will offer such a contextual reading, and I will defend the view that, in Metaphysics Z.10-11, Aristotle provides us with an elaborate argument for the purity of forms.

Roughly, on my interpretation of Z.10-11, which I will call hierarchical purism, each composite has two definitions, one in terms of its form alone, and one in terms of both its form and its matter. Which definition we should choose depends on how we consider the composite, either only insofar as it has a form or insofar as it has both a form and matter. Moreover, since, if we consider a composite only insofar as it has a form, it should be defined without reference to its matter, forms are pure.

I will begin by characterizing the 'impurist' view that forms involve matter and three versions of the opposing 'purist' position: Hard purism, soft purism, and my hierarchical purism (Section 1). Next, I will argue that the two extant versions of purism, hard and soft purism, are unsatisfactory as interpretations of Z.10-11. For neither view can account for Aristotle's vexing tendency to insist both that composites should be defined with reference to their formal parts alone, and that they should be defined with reference to their material parts as well (Sections 2 and 3). Nonetheless, impurism does not fare better either (Section 4). Rather, I will argue that only hierarchical purism can deliver a coherent reading of Z.10-11, and I will explain why its implication that each composite has two definitions should not frighten us (Section 5). Finally, I will sum up my results and explain why, if hierarchical purism is true, Aristotle's forms are pure (Section 6).

Of course, the overall question whether Aristotle's forms are pure or impure does not depend solely on how we read Metaphysics Z.10-11. Here, I will defend the restricted thesis that, in Z.10-11, Aristotle argues for the purity of forms. Indeed, in order to keep a clear view of Z.10-11, I will avoid relying on external evidence directly concerning the purity of forms, especially from De anima. ${ }^{2}$ How the results reached in Z.10-11 relate to other texts is a question for another day.

2. In De anima, perhaps the most important passages are DA I.1, 403a3-b19, and DA II.1, 412a1-b9, where Aristotle discusses the definition of soul. For an impurist interpretation of $D A$ I.1, see Charles (2008) and (2009), and for a purist response Caston (2008). 


\section{Purism and Impurism}

Before we delve into the text of Metaphysics Z.10-11, we need an outline of our exegetical options. Four options will be considered in this paper: impurism, hard purism, soft purism, and hierarchical purism. While the former three interpretations have been defended by other scholars, hierarchical purism is the new view I will develop here, with the ultimate goal of vindicating the purity of forms.

Sometimes, the claim that forms involve matter or are impure is spelled out in terms of the definition or essence of the form. Michail Peramatzis, for example, says that the form is defined with reference to matter, or that matter is part of the essence of the form. ${ }^{3}$ However, in Z.10-11, Aristotle rarely speaks of the definition of the form, rather than of the composite, and when he does so, he has in mind the definition of the composite in terms of the form. ${ }^{4}$ Impurism is better characterized by the conjunction of the following two schematic claims:

(1) The definition of a composite should mention only the form of the composite.

(2) The definition of a composite should mention the matter of the composite.

Taken together, those claims suggest that, as the impurist has it, the form of a composite is itself 'material', in a sense yet to be specified.

The two extant purist options are characterized by their rejection of either (1) or (2). Hard purists, such as Michael Frede and Günther Patzig, accept (1) but reject (2). That is, they think that, at least in Metaphysics Zeta, the definition of a composite mentions only its form but never its matter (Frede \& Patzig 1988: e.g., 211-213; Frede 1990; see also Devereux 2010; Menn 2001: 107-115; Wedin 2000: ch. 8). On the other hand, soft purists, such as W. D. Ross, Mary Louise Gill, and Robert Heinaman, accept (2) but reject (1). On their view, the definition of a composite should mention its matter, but they take that to imply that the definition mentions matter in addition to the form (Gill 1989: ch. 4; Heinaman 1997; Ross 1924: 197; see also Bonitz 1848-49: 333; Caston 2008; Ferejohn 1994; Morrison 1990).

As we will see, hierarchical purists should reject both (1) and (2), as they

3. He writes both that 'material parts are part of a form's essence' and that material parts are 'referred to in [the] definiens [of the form]' (Peramatzis 2011: 39).

4. For example, at the beginning of Z.11, Aristotle says that 'the definition is of the universal and the form' (1036a28-29). But that remark is made in service of the claim that one needs to distinguish the formal from the material parts of a composite since otherwise 'the account of the

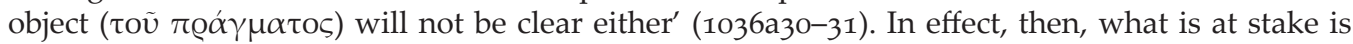
the definition of the composite in terms of its form rather than simply the definition of the form. Similar points apply to two passages in Z.10 (1035a17-22; 1035b31-1036a2). 
stand, and accept qualified versions of both. If a composite is considered only insofar as it has a form, it should be defined exclusively with reference to its form. But if the same composite is considered insofar as it has both a form and matter, it should be defined with reference to both its form and its matter. On hierarchical purism, then, each composite has two different definitions, and depending on how one considers the composite, one or the other definition should be chosen. Furthermore, the hierarchical purist takes those definitions to be hierarchically ordered: Strictly, only the purely formal definition of the composite is a definition at all because it states the essence of the composite. But in a looser sense of 'definition', the composite can be defined with reference to both its form and some of its material parts.

The force of the distinction between purism and impurism depends on how we specify 'matter' in (2). No impurist wants to say that the particular bits of matter into which a (sensible) composite perishes are parts of its form. 5 Terence Irwin (1988: 245-247) and Jennifer Whiting (1986: 372; 1991: 631), for example, insist that it is only the functional material parts of the composite, such as the hand of an organism, which are parts of its form. Peramatzis $(2011: 7,10)$ and David Charles, in turn, hold that none of the material parts of a composite are also parts of the form, neither the bits of matter into which the composite perishes nor its concrete functional material parts (nor even types of such concrete matter). Rather, some of the material features (or material 'ways of being') of composites are parts of their forms (Charles 2008: 10-15; 2009: 296-97; Peramatzis 2011: 41-42, 73, 98-99; 2015: 209-210). ${ }^{6}$ The purist, on the other hand, must take Aristotle to claim that neither the material parts of a composite nor its material features are parts of the form.7

Since the four exegetical options are characterized by their acceptance or rejection of claims about definition, a brief note on definitional language is in

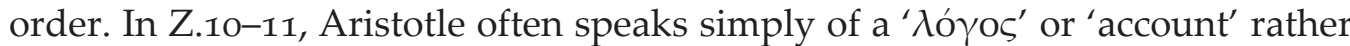
than of a 'ọ́ı $\mu$ ó $\varsigma^{\prime}$ or 'definition' even when he has in mind a definition. He alerts us to that feature of his exposition right at the beginning of Z.10 where he

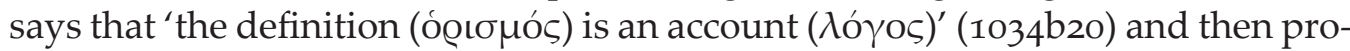

5. Impurists also hold that the intelligible matter of a geometrical object is part of its form, but they do not seem to differ in how they interpret that claim. We will return to geometrical objects in Section 3.

6. Peramatzis's examples for the relevant material features or ways of being include 'being made of a bulky mass which is (e.g.) malleable, solidifiable, and wrought-able' (2011: 7), and 'having living and fully functional hands which can perform successfully their relevant function' (2011: 98).

7. But the purist can allow that, in giving a definition of a composite solely in terms of its form, one will mention matter other than the matter of the composite. For instance, one can define a house purely formally as 'shelter for goods' where the goods are material, but not material parts or features of the house. 
ceeds to raise a puzzle concerning definitions using the language of 'accounts' (1034b20-24). Similarly, throughout Z.10-11, we should expect Aristotle to be interested in accounts of a special sort, namely, definitions, even though he does not bother to make that explicit at every turn of the argument.

On the other hand, Aristotle does not always use definitional language in the strictest sense. In the strictest sense, a definition is the account of the essence of a primary substance (Z.5, 1031a11-14). But in Z.10, Aristotle is happy to speak of 'defining' organs like the finger or mathematical objects like the acute angle, none of which are primary substances (1035b7-11; 1036b8-10). Hence, while Aristotle is interested in definitions throughout Z.10-11, those definitions may not all turn out to be definitions in the strictest sense. I will revisit that last point in Section 5 . With those caveats in mind, let us finally tackle the text.

\section{The Purist in Trouble}

The central difficulty for any interpreter of Metaphysics Z.10-11 is the perceived incoherence of Aristotle's view on the definition of matter-form composites. Sometimes, Aristotle asserts that only the formal parts of a composite should be mentioned in its definition (e.g., 1035a9-12; 1035a17-22; 1035b31-36a2; 1036a26-b7; 1037a21-29). At other times, he urges that some of the material parts should be mentioned too (e.g., 1035a22-25; 1036b21-32). One of the problems with purism has been that its two extant versions, that is, hard purism and soft purism, can make sense of only one or the other strand of Z.10-11. Thus, impurists have felt invited to reject purism wholesale. Here, I will characterize the weaknesses of both hard purism and soft purism by analysing a passage in Z.10 which I will call the 'Puzzling Passage' (1035a17-25). In the next section, I will argue that the problems arising from the Puzzling Passage for both brands of purism are amplified in Z.11.

The guiding question of Z.1o is 'whether the account of the parts must be present in the account of the whole' (1034b22-24). ${ }^{8}$ Aristotle quickly arrives at a first answer: The parts of the composite should be mentioned in its account or definition if (and only if) they are among its formal parts. For example, the letters should be mentioned in the definition of the syllable because they are among its formal parts, but the segments should not be mentioned in the definition of the circle because they are among its material parts (1035a9-12). ${ }^{9}$

8. See Menn (2001: 108-109) who stresses that the original question is whether the parts must be mentioned, not which parts, as is sometimes claimed.

9. In Z.10-11, Aristotle treats the segments as intelligible material parts of the circle which are 'closer to the form' than perceptible matter such as the bronze in which the form of circle might be instantiated (1035a13-14). He is most explicit about taking the segments to be intelligible material 
It is against that background that we should read the ensuing Puzzling Passage: ${ }^{10}$

[A] For ( $\gamma \dot{\alpha} \mathrm{Q})$ the line, too, even if, when divided, it perishes into the halves, or the human being [even if, when divided, it perishes] into bones and sinews and flesh, are not for that reason also from those [parts] as

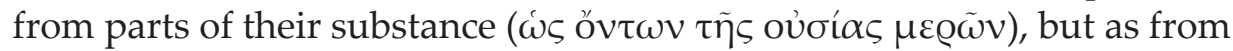

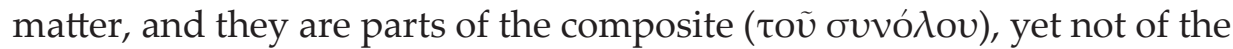
form and of that of which the account is; nor are they therefore in the accounts. [B] The account, then ( $\mu \dot{\varepsilon} v$ oũv), of such parts will be in [the accounts] of some things, but it must not be in [the accounts] of others if it is

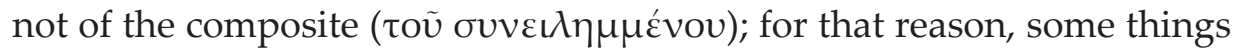
are from the parts into which they perish as from principles ( $\omega \varsigma \dot{\alpha} \varrho \chi \tilde{\omega} v)$, but others are not. (1035a17-24)

In Section [A], Aristotle follows the reasoning from before. Even though composites perish into their material parts, those material parts are not 'parts of their substance' or form (1035a20), and hence they should not be mentioned in their definitions. For example, a human being perishes into bones, sinews, and flesh, but those material parts are parts only of the composite, not of the form, and hence they should not be mentioned in the definition of the human being. ${ }^{11} \mathrm{Un}-$ fortunately, in [B], Aristotle appears to deny the claim made in [A]. The account of 'such parts', that is, seemingly, of the material parts into which a composite perishes, should be parts of the account or definition of the composite. ${ }^{12}$

Crucially, Aristotle uses different words for 'composite' in [A] and [B]. In [A], Aristotle calls the composite a 'oúvoגov' or 'whole', while in [B], he calls it a

parts in his discussion of semicircles in Z.11 (1036b32-37a5). On the other hand, in Z.10, the letters of the syllable are treated as its formal parts, except for the perceptible letters of particular perceptible syllables (1035a14-17). By contrast, in Z.17, Aristotle seems to take the letters of any syllable to be its material parts (1041b30-33).

10. All translations are mine. The 'for' (' $\gamma \alpha \dot{ } \mathrm{Q}^{\prime}$ ) at $1035 \mathrm{a} 17$ introduces the reason why the material parts of a particular sensible syllable should not be mentioned in the account of the syllable.

11. Aristotle must have in mind particular composites. For only particular composites perish into their material parts. That raises the question how Aristotle can allow himself to speak of 'definitions' here (or, more generally, of 'accounts'), given that the objects to be defined are particulars. I will return to that question in Section 5.4.

12. The transition from $[\mathrm{A}]$ to $[\mathrm{B}]$ is tricky. If one takes ' $\mu \dot{\varepsilon} v$ oṽ $v^{\prime}$ inferentially, say, as a 'therefore', Aristotle infers from the discussion in [A] that the account of 'such parts' is in the account of some things but not of others. But that inference makes sense only if, as the hard purist has it, 'such parts' refers to the formal parts. Yet, the reference seems to be to the material parts. (We will return to that point shortly.) My suggestion is that we take ' $\mu \dot{\varepsilon} v$ oũ $v^{\prime}$ not inferentially, but simply as continuing Aristotle's train of thought. Thus, we do not have to assume that [B] draws an inference from [A]. Rather, [B] continues where [A] left off, albeit in a quite different vein. That also allows us to take 'such parts' to refer to the material parts. 


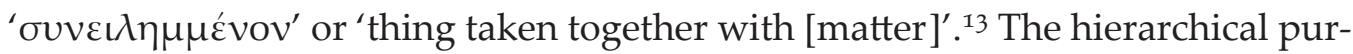
ist interpretation of Z.10-11 will take its cue from that verbal distinction. But for now, it is worth noting a difference which the verbal distinction does not track: It does not track an extensional difference. For among the 'things taken together with matter' is Kallias, that is, a human being, who perishes into flesh and bones (1035a33). In [A], then, we are told that the composite human being should not be defined with reference to the material parts into which it perishes, but in [B], we are told that it should be so defined; and similarly for other composites.

Neither hard purism nor soft purism can make good sense of the Puzzling Passage. Hard purists thrive on [A] which suggests that only the formal parts of a composite should be mentioned in its definition. But they are troubled by [B] where Aristotle seems to claim that the composite should be defined with reference to some of its material parts, too. On the other hand, soft purists are happy with [B] which is in line with their view that composites should be defined with reference to both their formal and material parts. But soft purists are dismayed by the claim in $[\mathrm{A}]$ that composites should be defined only with reference to their formal parts.

On behalf of hard purism, Michael Frede and Günther Patzig (1988: 180) have responded that, at the beginning of [B], 'such parts' (1035a22), refers all the way back to parts like the letters of the syllable (1035a11), that is, to the formal, not the material parts of the composite. On their reading, then, Aristotle consistently argues that only the formal parts of a composite are to be mentioned in its definition. But as several scholars have pointed out, it is hardly credible that 'such parts' refers back to the formal parts rather than the material parts discussed in the immediately preceding passage (Bostock 1994: 150; Heinaman 1997: 285-289; Morrison 1990: 136-137).

Revising the Frede-Patzig response, Daniel Devereux (2010: 172-173) has suggested that 'such parts' refers to the parts into which a composite is divided, including both its material and its formal parts. Moreover, on Devereux's reading, it is only the formal parts which are mentioned in the definition of the composite. But if that were right, Aristotle's claim that only some things are from the parts into which they perish as from principles would be puzzling. For surely, all things are from their formal parts as from principles. Aristotle's claim must be that only some things are from the material parts into which they perish as from principles. Hence, according to [B], the parts to be mentioned in the definition of the composite must be material parts.

On the other hand, soft purists have tried to restrict [A] to the definition of forms: The form of a composite should be defined without reference to the

13. Aristotle gives two different explications of the latter expression, speaking of 'those things which are the form and the matter taken together' (1035a25-26) and what is 'taken together with matter' (1035a34-b1). 
material parts into which the composite perishes. But, as we are told in [B], the composite itself should be defined with reference to those material parts (Bonitz 1848-49: 333; Gill 1989: 127; Heinaman 1997: 291-292; Ross 1924: 197).

Yet, [A] concerns the definition of the composite, not merely of the form. For Aristotle is interested in the definition of things which perish into their material parts, which must be composites. He claims that those material parts are not parts of the substance of the composites, and hence they are not parts of the form, that is, 'of that of which the account is' (1035a21). But the force of that claim is not merely that the material parts are not parts of the form and should not be mentioned in the definition of the form, but also, and by the same token, that they are not parts of that in terms of which the composite is defined. Similarly, when Aristotle argued earlier that the segments should not be mentioned in the definition of the circle because they are among its material parts, he must have meant the composite circle. For the form of the circle does not have any non-formal parts which could count as its parts. ${ }^{14}$

In short, while hard purists cannot accommodate the suggestion in part [B] of the Puzzling Passage that the material parts of a composite should be mentioned in its definition, soft purists cannot account for [A] where Aristotle claims that composites should be defined with reference to their formal parts alone. Those difficulties for both extant varieties of purism are amplified in Z.11, as we will see next.

\section{Purist Troubles Amplified}

In the following, I first want to argue that the main body of Z.11 mirrors the argumentative structure of the Puzzling Passage in Z.1o. Consequently, both hard purism and soft purism struggle to give a coherent reading of Z.11. What I call the 'main body' of Z.11 extends from the beginning of the chapter through the 'Mathematical Passage' or 'MP' (1036b7-20) and the 'Socrates the Younger Passage' or 'SYP' (1036b21-32). Roughly, the introductory section of Z.11 (1036a26-b7) is in line with part [A] of the Puzzling Passage, while the MP and the SYP reflect part $[\mathrm{B}]$ of that passage. Second, I will argue that the relevant part of the summary of Z.4-11 (1037a21-33), too, displays that same dialectic.

\subsection{The Main Body of Z.11 (1036a26-b32)}

Z.11 starts out with a puzzle: 'One wonders reasonably both what sort [of parts]

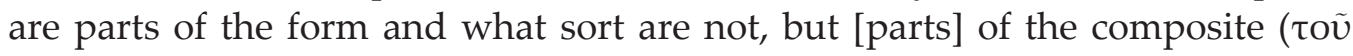

14. Devereux develops that objection to soft purism at greater length (2010: 171-172). 


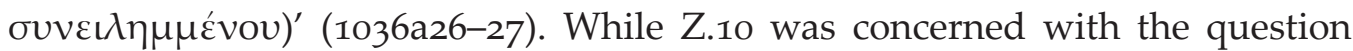
whether the parts of a whole should be mentioned in its definition, Z.11 aims at distinguishing the formal from the material parts of the composite. The way Aristotle sets up that task favours the hard purist. For Aristotle claims that 'the definition is of the universal and the form' (1036a28-29), apparently assuming that only the formal parts of a composite should be mentioned in its definition (1036a29-31). In the same vein, Aristotle goes on to claim that the flesh and bones of a human being are not 'parts of the form and account' (1036b5), with the implication that only the parts of the form should be mentioned in the definition of the human being. ${ }^{15}$

Overall, then, the introductory section of Z.II proceeds as predicted by the hard purist and, by the same token, spells trouble for the soft purist. But hard purism, too, begins to face problems when, in the ensuing Mathematical Passage, Aristotle objects to his opponents' practice of defining geometrical objects: ${ }^{16}$

Since that seems to be possible, but since it is not evident when, some are already puzzled also about the circle and the triangle that it is not appropriate for them to be defined (ó@í $\varepsilon \sigma \theta \alpha \mathrm{\iota}$ ) by lines and the continuous, but that all of those things, too, are said just as if they were flesh and bones of the human being, and bronze and stone of the circle ${ }^{17}$; and they lead back ( $\dot{\alpha} v \alpha$ ' $\gamma \mathrm{O} v \sigma \mathrm{\iota}$ ) all things to the numbers, and they say that the account of a line is that of two. (1036b7-13)

Hard purists take Aristotle still to be concerned with distinguishing the formal from the material parts of the composite (Devereux 2010: 177; Frede \& Patzig 1988: 206). On their reading, Aristotle's opponents claim that geometrical objects should be defined without reference to 'lines and the continuous' (1036b9-10) because they mistake them for material parts. ${ }^{18}$ But according to Aristotle, as presented by hard purism, geometrical objects should be defined with reference to the continuous because the continuous is one of their formal parts (Frede \&

15. I take it that Aristotle affirms that flesh and bones are not parts of the human form even though he expresses that claim as part of a double question (pace Bostock 1994: 160; Peramatzis 2011: 93). For Aristotle often uses double questions to affirm what is asked in the second question, e.g., in Meta. Z.4, 1030a2-3; Meta. Ө.7, 1049a1-3; Phys. IV.13, 222a29-30; DA II.12, 424b14-16; EN IX.13, 1165 b14-15, 1165 b17-18, 1165b23-24. However, even for impurists, it should be uncontroversial that flesh and bones are not parts of the human form since, in Z.10-11, flesh and bones are treated as the parts into which a human being perishes (see also 1035a17-19).

16. The opponents are Platonists and/or Pythagoreans, but their exact identity is uncertain. See Ps.-Alexander (512.23-24), Bonitz (1848-49: 339), Ross (1924: 202).

17. With Frede \& Patzig (1988: 207), I follow the manuscript tradition EJ here which has 'circle' rather than 'statue'.

18. I suggest that a line is simply the continuous in one dimension (see Meta. K.3, 1061a33-34), and I will drop reference to the 'lines' except where relevant. 
Patzig 1988: 201). That last claim will lead to problems for hard purism if we look beyond the MP.

At the beginning of the SYP, Aristotle describes the mistake criticized in the MP thus:

So, that the issues about definitions pose some problem (č $\chi \varepsilon \iota \tau \iota v \dot{\alpha}$ $\dot{\alpha} \pi$ o@í $\alpha v)$, and for what reason, has been said. Hence it is needless trou-

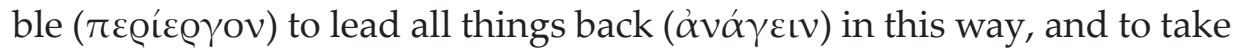
away the matter; for presumably some things are this in this or these be-

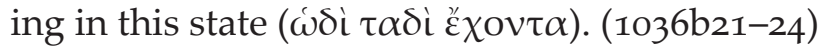

It seems that, in defining geometrical objects in terms of numbers, and without reference to the continuous, Aristotle's opponents define geometrical objects with reference to their formal properties alone, 'taking away the matter' (1036b23) from the definition. ${ }^{19}$ If that impression is not deceptive, hard purism is in trouble. For hard purists claim that the continuous is a formal part of a geometrical object. But if Aristotle also takes the continuous to be the matter of geometrical objects, hard purists must admit that some of the material parts of a geometrical object are also among its formal parts, which is the impurist view (Peramatzis 2011: 58-59; Whiting 1991: 626).

In response, Devereux (2010: 180) has suggested that Aristotle complains not that his opponents omit reference to what is the matter of geometrical objects by his own lights, but merely to what they mistake for matter. Hence, Aristotle's point is that the continuous is a non-material formal part of geometrical objects, just as the hard purist maintains. However, if Devereux is right, according to Aristotle, the continuous should not count as the matter of geometrical objects. But there is good evidence that Aristotle does take the continuous to be the matter of geometrical objects, namely, their intelligible matter.

In Z.10-11, Aristotle explicitly analyses geometrical objects as composites of a geometrical form and intelligible matter (1036a2-12; 1036b32-37a5). He contrasts intelligible matter with perceptible matter (1036a9-12; 1037a4-5), and he seems to think of intelligible matter as something like pure spatial extension which 'is present in perceptible things not qua perceptible' (1036a11). ${ }^{20}$ Indeed, elsewhere, he identifies the matter of geometrical objects with the continuous. ${ }^{21}$

19. At least for the sake of argument, then, Aristotle takes numbers to be forms of geometrical objects. He treats numbers as forms of geometrical objects elsewhere, too. See Meta. H.2, 1043b3334, and DA III.4, 429b18-20.

20. See Mueller (1970) for a classic discussion.

21. In DA III.4, for instance, he says that the straight 'is like the snub', and, unlike the essence of the straight, the straight itself is 'with [the] continuous' (429b18-22). See also De caelo I.1, 268a89, and Meta. K.3, 1061a32-35. 
Moreover, the mention of 'lines' at 1036b9 is helpful. For in his summary of Z.10, Aristotle contrasted the perceptible with the mathematical right angle, treating the lines as the (intelligible) matter of the latter in analogy with the bronze of the bronze right angle (1036a20-22).

Hence, it seems that, for Aristotle himself, the continuous is the (intelligible) matter of geometrical objects. But then Devereux's response fails. It is not just that Aristotle's opponents mistake the continuous for matter. Rather, they omit reference to what, by Aristotle's own lights, is matter, and they are wrong for doing so. According to Aristotle, geometrical objects should be defined with reference to their (intelligible) matter. But if all the parts of an object mentioned in its definition must be formal parts, as the hard purist has it, some of the formal parts of a geometrical object are also material parts, and hence geometrical forms must be impure.

Analogous problems arise for the hard purist interpretation of the SYP. The section at 1036b21-24 refers not only back to the MP but also forward to the SYP. Aristotle generalizes his conclusion from the MP: One should not remove (reference to) the matter from the definition of anything which is 'this in this or these being in this state' (1036b23-24), that is, 'this form in this matter' or 'these material parts in this (formal) state'. He then relies on that general principle to confront the Platonist Socrates the Younger: ${ }^{22}$

The comparison, then, concerning the animal which Socrates the Younger

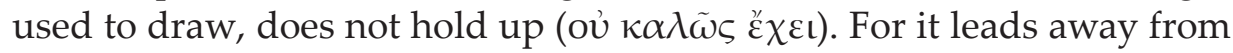
the truth and makes one suppose that the human being can be without its parts, just as the circle without the bronze. But the case is not similar; for the animal is something perceptible ( $\alpha i \sigma \theta \eta \tau o ́ v)$, and it cannot be defined (óí $\sigma \alpha \sigma \theta \alpha \mathrm{l}$ ) without motion, nor therefore without its parts being in a certain state. For the hand is not a part of the human being in just any state, but only the hand which is capable of fulfilling its function, inasmuch as it is ensouled; but if it is not ensouled, it is not a part. (1036b24-32)

Prima facie, Aristotle's line of reasoning is as follows: Socrates the Younger is an extreme exponent of the view rejected in the MP. He wants to define not only geometrical objects but even sensible objects without reference to their matter. Hence, he treats human beings, and animals more generally, in analogy with the (mathematical) circle. Circles are intelligible composites (1036a3-4) and can be defined without reference to perceptible matter. Similarly, according to Socrates

22. Plato introduces Socrates the Younger as a silent character in the Theaetetus and the Sophist, and as the main interlocutor in the Statesman. See Kapp (1923) for a discussion of Socrates the Younger. 
the Younger, animals can be defined without reference to perceptible matter. But, Aristotle objects, there is a disanalogy: Animals, unlike (mathematical) circles, are perceptible objects. ${ }^{23}$ Hence, the animal 'cannot be defined without motion, nor therefore without its parts being in a certain state' (1036b29-30). ${ }^{24}$

That reading, if correct, is disastrous for the hard purist. For the hard purist claims that sensible objects should be defined with reference to their formal parts alone. Hence, if they should be defined with reference to their perceptible matter too, some of their formal parts must be material as well, and impurism is true. In order to avoid that consequence, Frede and Patzig have attempted to show that, according to Aristotle, animals should not be defined with reference to their material parts. Rather, Aristotle criticizes Socrates the Younger because his position may mislead one into thinking that forms can exist without matter. According to the hard purist, then, animals should be defined with reference to the capacities of their souls alone, such as the capacity for perception. The material bodily parts of the animal are not explicitly mentioned in its definition, but their existence is implied since they are required for the animal to have the relevant capacities (Frede 1990: 119-121; Frede \& Patzig 1988: 209-210).

However, the issue of 'taking away the matter' (1036b23) with which both the MP and the SYP are occupied, is a puzzle 'about definitions' (1036b21), an instance of which has been stated as a puzzle 'about the circle and the triangle that it is not appropriate for them to be defined by lines and the continuous

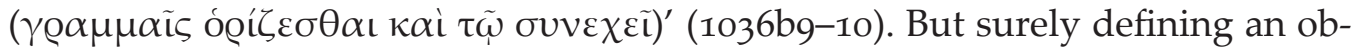
ject by the continuous has to involve explicit reference to the continuous, and similarly, one would think, for other instances of the puzzle. For instance, the puzzle whether the definition of an animal should refer to its perceptible matter must be concerned with an explicit definition of the animal no less than the puzzle whether the definition of a geometrical object should refer to its intelligible matter. Plausibly, then, Aristotle claims that the animal should be explicitly defined in terms of its material parts, contra Frede and Patzig.

Reformist hard purists admit that last point but draw on the fact that, in the SYP, Aristotle discusses the relation between the whole and its functional parts. In that respect, as we will see in detail below, the SYP importantly differs from the Puzzling Passage, where Aristotle was interested in the relation between a whole and the bits of matter into which it perishes. Some hard purists, then, hold

23. We should keep the reading ' $\alpha i \sigma \theta \eta \tau o ́ v '$ ' or 'perceptible', as transmitted by all manu-

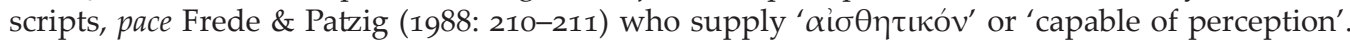
For Aristotle's point is precisely to contrast perceptible with intelligible objects: Intelligible objects, as he argued in the MP, should be defined with reference to their intelligible material parts, but not to any perceptible matter.

24. For the definitional connection between (perceptible) matter and motion, see also Meta. E.1, 1026a2-3, to which we will return in Section 5 . 
that the functional parts mentioned in the SYP, such as the hand, are not 'material' parts at all, properly speaking, and can be parts of the form (Chiaradonna 2014: 384-388; Devereux 2010: 183-184; Wedin 2000: 338). Yet, Aristotle speaks of the functional parts of sensible composites as their matter, as we will see in more detail later. ${ }^{25}$ Moreover, if the hard purist admits that the functional parts of a composite are parts of the form, and merely insists that those are not 'material' in the right way, the distinction between hard purism and impurism is in danger of becoming merely notational. ${ }^{26}$ Overall, therefore, while hard purism fared well as a reading of the introductory section of Z.11, it is difficult to sustain as an interpretation of the MP and the SYP.

Unlike the hard purist, the soft purist is not troubled by the MP and the SYP. For unlike the hard purist, the soft purist accepts that a composite can be defined with reference to its non-formal material parts. Hence, the material parts with reference to which composites are said to be defined in the MP and the SYP need not be formal parts, and neither geometrical forms nor forms of sensible objects turn out to be impure. Of course, the details of the soft purist reading of those passages are not trivial. As we will see in our discussion of hierarchical purism, additional work is needed to show that there can be any sort of account of a composite which mentions its material parts. But in general terms, soft purists can take the MP and the SYP to support their view: Composites should be defined with reference to some of their material parts, and the point of that conclusion is precisely that those material parts are not formal parts of the composites (Gill 1989: 133-136; Heinaman 1997; Ross 1924: 203).

That said, we should not forget that the soft purist had trouble accounting for the implication in the introductory section of Z.11 that the definition of a composite is a definition solely in terms of its form. That issue will arise more forcefully in the summary of Z.4-11 to which we are turning now.

\subsection{The Summary of Z.4-11 (1037a21-b7)}

At first sight, the summary of Z.4-11, or better, that part of it which is concerned with Z.10-11 (1037a21-33), supports hard purism against soft purism. However, underneath its surface, the summary will be seen to display the same structure as the Puzzling Passage in Z.1o and the main body of Z.11, and hence to be difficult for both hard and soft purists.

Hard purism rests largely on what I will call the 'substance claim' in the summary:

25. See, e.g., Z.10, 1035b11-12; 1035b20-25. I will return to those passages in Section 5.4.

26. Irwin's (1988: 245-247) brand of impurism, as we will see, takes the SYP precisely the way suggested by our reformist hard purists, except for the claim that those parts are not 'material'. 
But of [the composite substance] there is an account in a sense and there is not: For with its matter, there is not (for [matter] is indefinite ( $\alpha$ ó but in accordance with primary substance there is, for instance, of human being, the account of the soul. (1037a26-29)

Here, Aristotle says explicitly that the only definition of a composite is in accordance with its primary substance or form, which is just the hard purist thesis. As we will see below, a later remark in the summary will qualify that claim and cast doubt on whether the summary provides straightforward evidence for hard purism. But first, let us consider how soft purists try to make sense of the substance claim.

As far as I am aware, there have been three direct soft purist responses to the substance claim: First, Ross (205) holds that only prime matter is excluded from the definition of the composite because only prime matter is indefinite. Second, Heinaman (1997: 295) argues that only the definition of the form must not refer to the matter of the composite, while the definition of the composite can, or should, refer to its matter. Third, Michael Ferejohn (1994: 315-316) has suggested

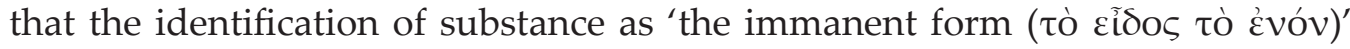
(1037a29) implies that not only the form but also the matter of the composite should be mentioned in its definition.

None of those responses are convincing. As for Ross, Aristotle treats matter quite generally as 'indefinite', not just prime matter (if Aristotle even has a notion of prime matter) ${ }^{27}$ Hence, there is no reason to think that Aristotle's claim here is restricted to prime matter. Heinaman's answer, in turn, does not succeed because the substance claim explicitly concerns the definition of the composite, not just its form. Nor is Ferejohn's suggestion any more successful. For even if forms are immanent in matter, it may be that the composite should be defined without reference to the matter in which the forms are immanent. Unsurprisingly, then, soft purism cannot accommodate the substance claim any more than other instances of the same claim found in part [A] of the Puzzling Passage or the introductory section of Z.11 (see also Z.10, 1035b31-36a2).

That said, the summary as a whole does not support hard purism either. For Aristotle follows up on the substance claim as follows: 'But in the composite substance, such as snub nose or Kallias, the matter will be present too' (1037a32-33). Superficially, that claim does not have any definitional import, but it appears to refer us back to a passage which does. The only other place in Z.10-11 where Kallias is mentioned (in tandem with the snub) is in the aftermath of part [B] of the Puzzling Passage. There, both the snub (1035a26) and Kallias (1035a33) are cited as examples of 'things taken together with matter' which should be defined

27. See for example Meta. $\Theta .7$, 1049a36-b2. 
with reference to their material parts. Since Aristotle makes the effort to remind us of that earlier passage, presumably the definitional claim made there is still in place (see Gill 1989: 136-137). But if that is right, even though the substance claim is in line with hard purism, the summary as a whole is not. For hard purism cannot account for the implied definitional claim at 1037a32-33 any more than for part [B] of the Puzzling Passage.

Hence, the summary, no less than the Puzzling Passage and the main body of Z.11, exhibits the very dialectic which has proven so troublesome: First, Aristotle claims that the composite should be defined with reference to its formal parts alone, but then he goes on to claim that some of its material parts should be mentioned too. Neither hard nor soft purism sits well with that dialectic. If impurism can do better, and if there are no further purist alternatives, we may have good reason to abandon purism.

\section{Impurism}

Impurists agree with hard purists that the definition of a composite is a definition solely in terms of its formal parts. But what presented itself as a difficulty for the hard purist, namely, that Aristotle also claims that the composite should be defined with reference to its matter, is welcomed by the impurist. Indeed, impurism promises a happy synthesis of hard and soft purism: Aristotle is expected to claim both that only the formal parts of a composite should be mentioned in its definition and that its matter should be mentioned. For some material parts, or at least some material features, of the composite are parts of its form.

Still, having spelled out the impurist reading of Z.10-11, I will argue that it fails no less than hard and soft purism. Instead, as we will see in the next section, we have to revert to a version of purism, namely, hierarchical purism.

\subsection{The Impurist Reading of Z.10-11}

Let us first return to the Puzzling Passage in Z.10. In part [A] of that passage, Aristotle claimed that composites should be defined without reference to the material parts into which they perish. For example, a human being should be defined without reference to its flesh and bones. But in part [B] of the same passage, Aristotle said that composites should be defined with reference to the material parts into which it perishes. For instance, Kallias should be defined with reference to his flesh and bones. The impurist may aim to resolve that apparent inconsistency by appeal to the material principles of the composite..$^{28}$

28. As David Charles has suggested (in conversation). 
Remember that some impurists distinguish between the particular bits of matter into which a composite perishes and the material features of the composite. Only the latter are parts of the form. That distinction promises an elegant solution to our puzzle: In [A], Aristotle argues that the particular bits of matter into which a composite perishes should not be mentioned in its definition. But in [B], Aristotle speaks of material parts as 'principles' (1035a24), and the impurist can take those to be material features of the composite rather than parts into which the composite perishes. Thus, Aristotle argues consistently that the material parts into which a composite perishes should not be mentioned in its definition, and are not parts of its form, but that the material principles or features of the composite should be mentioned in its definition and are parts of its form. ${ }^{29}$

The impurist takes the MP and the SYP in Z.11 to confirm the same sort of point. First, according to the impurist, Aristotle argues in the MP that the continuous is both a formal and a material part of the geometrical composite, and hence that geometrical forms are impure, as seen in our discussion of hard purism (Peramatzis 2011: 58-59; Whiting 1991: 626). More importantly, the SYP is taken to directly support impurism about the forms of sensible objects. According to Irwin (1988: 245-247) and Whiting (1986: 372; 1991: 631), Aristotle commits himself to the view that the animal should be defined with reference to its functional material parts. On Peramatzis's version of impurism, the animal, or human being, should be defined with reference to its material features, such as 'having fully functional hands' (2011: 98-99; 2015: 209-210; see also Charles 2008: 15-17, discussing the implications of DA I.1). But on either view, forms of sensible objects turn out to be impure. For if the animal is defined with reference to its functional matter or material features, and it is defined exclusively with reference to its formal parts, the functional matter or material features must be formal parts of the composite.

Thus, apparently, impurism can draw on the MP and the SYP as support no less than soft purism. But unlike soft purism, impurism does not seem to have any trouble with passages like the summary of Z.4-11 where Aristotle claims that only the formal parts of a composite should be mentioned in its definition. For on impurism, it is true that the definition of a composite mentions only its formal parts, not the indefinite non-formal material parts of the composite (Peramatzis 2011: 51). Nonetheless, ultimately impurism does not work as an interpretation of Z.10-11.

29. Similarly, Peramatzis (2011: 46-47) argues that, in the case of the syllable mentioned at 1035a9-14, the letters of the syllable are neither material constituents of the token syllable nor of the type syllable, but rather material features or ways of being. 


\subsection{Why Impurism Fails}

A first problem with impurism arises from the MP. According to the impurist, Aristotle's claim in the MP is that the lines and the continuous are both formal and material parts of the geometrical object, and hence that the geometrical form is posterior to some of the material parts of the composite, namely, to the lines and the continuous. But in the summary of Z.10, Aristotle claims that 'the right angle without matter is posterior to the parts in the account, yet prior to the parts in the particulars' (1036a22-23, my italics). In the case of the intelligible right angle, then, the right angle without matter, that is, the form of the right angle, is posterior to its own parts but prior to the intelligible material parts of the intelligible composite, namely, its lines (1036a21). Aristotle effectively restates the same point in Z.11 when he claims that the intelligible semi-circles 'will not be parts of the universal circle but of the particulars' (1037a2-3). It would be surprising if Aristotle argued for the negation of that claim in the MP, as the impurist has it.

But the main objection concerns the impurist reading of both the Puzzling Passage and the SYP. As for the Puzzling Passage, the impurist move was to distinguish between the material parts into which a composite perishes and its material principles. However, it is doubtful that such a distinction can be found in the passage. Aristotle says, 'Some things are from the parts into which they perish as from principles ( $\omega \varsigma \dot{\alpha} \varrho \chi \tilde{\omega} v)$, but others are not' (1035a24-25). It seems quite clear that the principles are not distinguished from the material parts into which composites perish but identified with them. That would also fit Aristotle's treatment of the bits of matter from which a composite comes to be as its material principle in the Physics (see, e.g., Phys. I.7, 190b17-91a3).

If that is right, the impurist faces the same difficulty as the hard purist. Although the impurist thinks that either the functional matter or the material features of the composite should be mentioned in its definition, and hence are among the parts of its form, the impurist wants to exclude reference to the bits of matter into which the composite perishes from its definition. Just like the hard purist, therefore, the impurist has trouble accommodating [B], where Aristotle tells us that the composite is defined with reference to the material parts into which it perishes.

Peramatzis (2011: 49) recognizes that problem and argues that [B] is concerned merely with the existential dependence of composites on the material parts into which they perish. However, in [B], Aristotle is explicitly concerned with 'accounts' of composites, not merely with an existential dependence relation. After all, he claims that 'the account of such parts will be in [the accounts] of some things' (1035a22-23). The Puzzling Passage, far from supporting impurism, is in fact a problem for the view. 
A similar difficulty comes about for the impurist reading of the SYP. Recall what Aristotle says in the crucial section of the SYP:

[T] he animal is something perceptible ( $\alpha \grave{i \sigma \theta \eta \tau \tau o ́ v), ~ a n d ~ i t ~ c a n n o t ~ b e ~ d e-~}$ fined (óí $\sigma \alpha \sigma \theta \alpha \mathrm{\iota}$ ) without motion, nor therefore without its parts being in a certain state. For the hand is not a part of the human being in just any state, but only the hand which is capable of fulfilling its function, inasmuch as it is ensouled; but if it is not ensouled, it is not a part. (1036b28-

32)

There are two impurist options here. Prima facie, Aristotle tells us that the animal should be defined with reference to 'its parts being in a certain state', such as the ensouled hand 'capable of fulfilling its function'. That is, prima facie, Aristotle's claim is that the animal should be defined with reference to its concrete functional material parts, such as the (ensouled) hand, and it is those concrete functional material parts which are parts of the form. That is the first impurist option, defended by Irwin (1988: 246).

The problem with the first impurist option is that, in Z.10, Aristotle explicitly denies that functional material parts are prior to the form or soul of an organism. Having identified the soul as the substance or form of the animal (1035b14-16), he says that 'the parts [of the soul], either some or all of them, are prior to the composite animal, and similarly in each case, but the body and its parts are posterior to that substance' (1035b18-21). Indeed, in the SYP itself, Aristotle seems to recall that doctrine. For 'if [the hand] is not ensouled, it is not a part [of the human being]' (1036b32), which suggests that the hand of a human being is posterior to its soul. Assuming that Aristotle maintains a coherent account of the relation between body and soul in Z.10-11, we should reject an interpretation of the SYP which makes it straightaway inconsistent with the doctrine stated in Z.10.

The second impurist option, advocated by Peramatzis, avoids the problem just mentioned. On that version, it is not the concrete functional material parts of a composite (nor types of such parts), which are parts of the form (Peramatzis 2011: 10), but rather material features, such as 'having living and fully functional hands which can perform successfully their relevant function' (Peramatzis 2011: 98). While the functional material parts of the composite may be posterior to the soul, the relevant material features are prior. The force of the SYP, then, is that the animal should be defined with reference not to its (functional) material parts but to its material features.

That impurist move is sophisticated, but perhaps too sophisticated for the SYP. For Aristotle is quite explicit that the animal cannot be defined 'without its parts being in a certain state' (1036b3o). It is true that the state of the parts is important for the definition, and perhaps we can understand the state of the parts 
as a material feature of the organism such as 'having fully functional hands'. But it is equally true that the parts themselves are important for the definition: It is the parts in some state which should be mentioned (see Devereux 2010: 180). Hence, for the brand of impurism we are considering, the SYP (much like the Puzzling Passage) shows too much, namely, that the concrete material parts (or perhaps types thereof) should be mentioned in the definition of the composite, and so, by impurist lights, are parts of the form. Overall, then, neither of our two impurist interpretations of the SYP is persuasive.

Where does that leave us? On the one hand, neither hard purism nor soft purism promises a coherent reading of Z.10-11. On the other hand, impurism cannot handle crucial passages, such as the Puzzling Passage or the SYP, either. I will argue next that hierarchical purism offers a unified interpretation of Z.10-11 which avoids the problems encountered so far. If that is right, we should take Z.10-11 to argue for the purity of forms after all.

\section{Hierarchical Purism}

We have come upon a tension in Z.10-11: Aristotle claims both that matter-form composites should be defined with reference to their forms alone, and that they should be defined with reference to their matter, too. The suggestion of hierarchical purism is that we can relieve that tension if we recognize that, in Z.10-11, Aristotle takes heed not only of the concerns of first philosophy but also of those of second philosophy or physics. According to Aristotle, if one considers a composite only insofar as it has a form (as the first philosopher does), one should define it with reference to its form alone. But if one considers a composite insofar as it has both a form and matter (which is the physicist's perspective), one should define it with reference to form and matter. In the case of intelligible composites, a similar distinction holds between the perspective of first philosophy and the perspective of geometry.

I will begin by motivating hierarchical purism as a response to the Puzzling Passage in Z.10, before extending the hierarchical purist reading to Z.11. I will then say more about first and second philosophy in Z.10-11, and I will discuss the implication that each composite has two definitions. In the next and final section, I will explain why, if hierarchical purism is true, forms turn out to be pure.

\subsection{Solving the Z.1o Puzzle}

Let us return to a passage early on in Z.10, which I will call the 'Hylomorphic Passage': 
If, then, one thing is matter, another form, and a further thing the composite ( $\tau \dot{\varepsilon} \dot{\varepsilon} \kappa \tau o u ́ \tau \omega \nu$ ), and if matter is substance and form and the composite, then there is a sense in which matter, too, is said to be a part of something, and there is a sense in which it is not, but those things

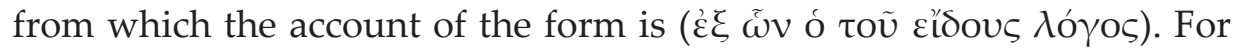
instance, flesh is not a part of concavity (for that is the matter in which it comes to be), but a part of snubness; and the bronze is a part of the

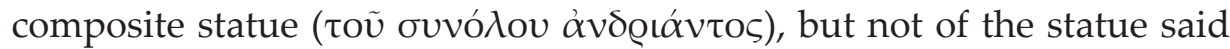

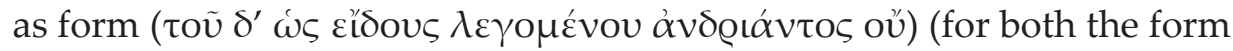
and each thing insofar as it has a form should be called [by the name of the thing], but the material by itself should never be called [by the name of the thing]). That is why the account of the circle does not contain the account of the segments, but the account of the syllable contains the ac-

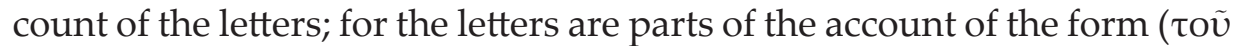

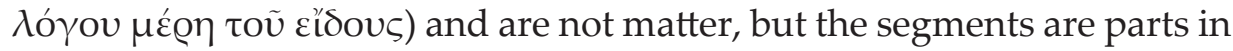
this way as matter in which [the form] comes to be. (1035a1-12)

Large parts of the passage are dedicated to explicating the thesis that there is a sense in which matter, too, is said to be a part of something, and there is a sense in which it is not' (1035a2-3). Aristotle distinguishes between a composite whole ( $\sigma u ́ v o \lambda o v)$ and an object 'said as form' (1035a7). Probably, Aristotle has in mind a linguistic distinction which he draws more clearly elsewhere. In Metaphysics H.3, for example, he says, 'We must not ignore that sometimes it is hidden whether the name signifies the composite substance or the actuality and the form' (1043a29-31; see also Meta. Z.8, 1033b17-18). Names such as 'statue' can either refer to a composite object, or to the form of that object. Thus, if we use a name to refer to a composite, then matter is a part of the referent, but if we use the same name to refer to a form, matter is not a part of the referent. Bronze is a part of the composite statue, but not of the form of the statue (see Bonitz 1848-49: 333; Bostock 1994: 148; Frede \& Patzig 1988: 174; Ps.-Alexander 503.16-17).

Aristotle goes on to state the principle more generally: 'Both the form and

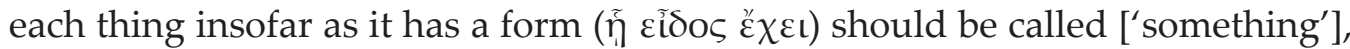
but the material by itself should never be called ['something']' (1035a7-9)..$^{30}$ By any name, we can refer either to the form of a composite or to the matter-form

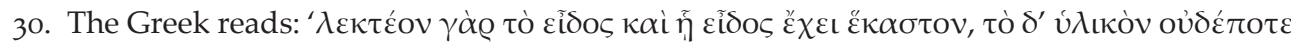
$\kappa \alpha \theta^{\prime} \alpha u ́ \tau$ ò $\lambda \varepsilon \kappa \tau \varepsilon \dot{o} v^{\prime}$. The sentence can be translated in two different ways. One option is to take 'each thing' (' $\varepsilon \kappa \kappa \sigma \tau o v^{\prime}$ ) to be part of the subject of the sentence and to supply part of the predicate, as I did. Alternatively, one can take 'each thing' to be part of the predicate and supply part of the subject, as in 'the form and [the thing] insofar as it has a form should be said to be each thing'. Furth $(1985: 23,119)$ offers both sorts of translation. I take 'each thing' to be part of the subject because I would expect 'insofar as it has a form' not to float free of any grammatical subject. 
composite itself insofar as it has a form, but never to the matter of the composite by itself. For instance, both the soul of Socrates and the composite of body and soul (insofar as it has a soul) can be called 'Socrates', but never the body by itself (for the example, see Meta. Z.11, 1037a5-10).

Crucially, Aristotle's principle leaves open another option. Even if we cannot use a name to refer to the matter of a composite by itself, we can use it to refer to the composite insofar as it has both a form and matter. Aristotle will take recourse to that option later, or so I will suggest. Equally importantly, however, only the composite insofar as it has a form is under consideration as of yet. The composite insofar as it has both a form and matter is disregarded for the time being. Hence, Aristotle can conclude - 'that is why (סı́)' (1035a9) - that only the formal parts of a composite should be mentioned in its definition, for instance, the letters in the definition of the syllable (but not the segments in the definition of the circle). After all, it is a natural thought that, if one considers a composite only insofar as it has a form, it should be defined with reference to its formal parts alone.

One might object that, in speaking of the composite insofar as it has a form, Aristotle does not mean to introduce a special way of considering the composite but merely to highlight that the composite is a definite, nameable object in virtue of its form..$^{31}$ On that point, I simply agree with the objector: In the Hylomorphic Passage, Aristotle does not draw a distinction between different ways of considering the composite. Rather, he simply assumes that composites are nameable, and definable, in virtue of their forms, without entertaining the possibility that the matter of the composite could play a role for explaining and defining what the composite is. As I see it, Aristotle's confusing move will be precisely that he drops that background assumption later, at least in some contexts.

With the Hylomorphic Passage in mind, then, we can understand the Puzzling Passage. As noted above, there is a curious shift in terminology between parts [A] and [B] of the Puzzling Passage. In [A], Aristotle refers to the composite

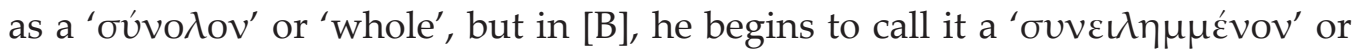
'thing taken together with matter'.$^{32}$ Moreover, in [A], he argues that the composite (under the description of 'whole') should be defined without reference to the material parts into which it perishes because they are not parts of its form. But in [B], he claims that the composite (under the description of 'thing taken together with matter') should be defined with reference to the material parts into which it perishes.

The terminological difference extends beyond the Puzzling Passage. In the Hylomorphic Passage, Aristotle called the composite a ' $\sigma u ́ v o \lambda o v$ ' or 'whole',

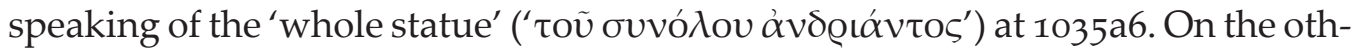

31. Many thanks to anonymous referee A for bringing up that point.

32. I am grateful to Jacob Rosen for helping me appreciate that distinction (in conversation). 
er hand, in the aftermath of the Puzzling Passage, he keeps speaking of the composite as a ' $\sigma \cup v \varepsilon i \lambda \eta \mu \mu \varepsilon$ vov' or 'thing taken together with matter' (1035a25-b3). Moreover, as discussed, Aristotle claims in the Hylomorphic Passage that only the formal parts of the composite should be mentioned in its definition. By contrast, after the Puzzling Passage, Aristotle insists that, for example, 'the clay statue perishes into clay and the sphere into bronze and Kallias into flesh and bones' (1035a32-33), with the implication that those composites should be defined with reference to the material parts into which they perish.

My suggestion is that the shift in terminology marks a shift in how Aristotle thinks about the composite, and that the latter shift explains his divergent claims about the definition of the composite. As long as he refers to the composite neutrally as a 'whole', Aristotle is interested in the composite only insofar as it has a form, and hence, in $[\mathrm{A}]$, he adheres to the claim from the Hylomorphic Passage that only the formal parts should be mentioned in its definition. On the other hand, as soon as Aristotle begins to call the composite a 'thing taken together with matter' in [B], he draws on an option absent from the Hylomorphic Passage, namely that we might use a name to refer to the composite insofar as it has both a form and matter. For example, by 'Kallias', we might mean the composite insofar as it has both a soul and flesh and bones. However, in that case, Kallias should be defined with reference to both his soul and the flesh and bones into which he perishes. ${ }^{3}$

Thus, the distinction between the 'ov́volov' or 'whole' in [A] and the

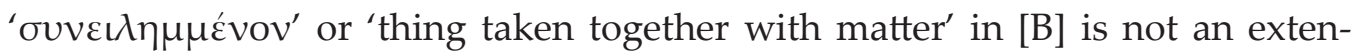
sional one between composites of different classes (let alone between forms and composites, as soft purists have it), but rather an intensional one between different ways in which composites can be considered, either only insofar as they have a form, or insofar as they have both a form and matter. Moreover, depending on how a composite is considered, it should be defined in different ways. Hence, on hierarchical purism, the tension in the Puzzling Passage finally disappears. If a composite is considered one way, it should be defined with reference to its formal parts alone, as we are told in [A], but if the same composite is considered another way, it should be defined with reference to its material parts as well, as we are told in [B].

None of that is to say that the terminological distinction between ' $\sigma u ́ v o \lambda o v$ '

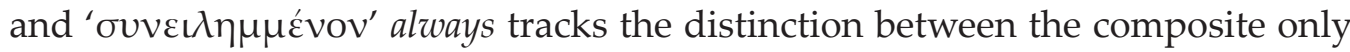
insofar as it has a form and the composite insofar as it has both a form and matter. ${ }^{34}$ Indeed, we will see shortly that, later in Z.11, 'oúvoגov' can refer to the

33. As the example of Socrates cited earlier shows, in Z.11, the body of a human being is treated as its matter, rather than, as here, the flesh and bones into which it perishes (1037a5-10). See Section 5.4 for more on that issue.

34. I thank anonymous referee $C$ for that clarification. 
composite insofar as it has both a form and matter. Nonetheless, in the Puzzling Passage, the terminological distinction points at the distinction between different ways in which the composite can be considered. In other passages, different markers will serve the same purpose, as I am about to discuss.

\subsection{Hierarchical Purism and Z.11}

I argued in Section 3 that both the main body of Z.11 (1036a26-b32) and the relevant part of the summary of Z.4-11 (1037a21-33) have the same dialectic structure as the Puzzling Passage. I will now explain how the hierarchical purist can account for Z.11 in just the way in which she has handled the Puzzling Passage.

To begin with, the introductory section of Z.11 (1036a26-b7) is reminiscent of part [A] of the Puzzling Passage. For Aristotle recalls the example of the human being from $[\mathrm{A}]$, once again to argue that the flesh and bones of the human being are not parts 'of the form and the account' (1036b5, recalling 1035a21). A similar point applies to the 'substance claim' at 1037a26-29 in the summary of Z.4-11 (that is, to the claim that the only definition of a composite is in accordance with primary substance). For the substance claim occurs in the context of what is effectively a paraphrase of the contention in [A] that the material parts of the composite are not parts of the substance of the composite (1037a24-26, paraphrasing 1035a19-21). Plausibly, then, both the introductory section of Z.11 and the substance claim in the summary concern the composite only insofar as it has a form, no less than [A].

In the Puzzling Passage, Aristotle's shift of interest from the composite considered only insofar as it has a form to the composite considered insofar as it has both a form and matter was marked verbally: In [A], Aristotle spoke simply of the 'whole', while in [B] he began to speak of 'the thing taken together with matter'. At the outset of Z.11, Aristotle calls the composite the 'thing taken together with matter' (1036a27), which suggests that the composite insofar as it has both a form and matter might play a role in the chapter. But in the main body of Z.11, he does not explicitly refer to the composite at all. Nonetheless, there is a linguistic marker that, as Aristotle proceeds beyond the introductory section of Z.11 to the MP and the SYP, his interest shifts to the composite considered insofar as it has both a form and matter.

At the beginning of the SYP, Aristotle says, pointing both back to the objects discussed in the MP and forward to the objects to be discussed in the SYP, that they are 'this in this or these in this state' (1036b23-24). The paradigm example for something which is 'this in this' is the snub, which is concavity in flesh (or in the nose) (see, e.g., Meta. E.1, 1025b32-33; Z.5, 1030b16-20; Z.10, 1035a4-6; Phys. II.2, 194a4-7; DA III.4, 429b14). But right after the Puzzling Passage, the snub was also treated as an example of a 'thing taken together with the mat- 
ter' (1035a26; similarly, at Meta. E.1, 1025b32). Presumably, then, when Aristotle speaks of things which are 'this in this' he is concerned with the composite insofar as it has both a form and matter no less than when he speaks of 'the thing taken together with its matter'. If that is right, unlike the introductory section of Z.11, the MP and the SYP target the definition of the composite considered insofar as it has both a form and matter.

The summary of Z.4-11 calls for a similar remark. We saw that, a few lines beyond the substance claim, Aristotle says that 'in the composite substance ( $\dot{\varepsilon} v$ $\tau \tilde{\eta}$ ovvó $\lambda \omega$ oưoí $\alpha$ ) the matter will be present too' (1037a32-33). Above I argued that Aristotle implicitly evokes the doctrine from Z.1o that composites should be defined with reference to their material parts. And even though Aristotle uses the word ' $\sigma$ vvolov' or 'whole' to evoke that earlier doctrine, the examples of the snub and Kallias, which were treated as 'things taken together with matter' in Z.10 (1035a26; 1035a33) suggest that here, unlike in the context of the substance claim, Aristotle has in mind the composite insofar as it has both a form and matter.

On those textual grounds, the hierarchical purist can extend her reading to Z.11. Both in the introductory section of Z.11 and in the context of the substance claim, Aristotle is interested in the composite only insofar as it has a form. Hence, he concludes (or assumes) that the composite should be defined with reference to its form alone. But in the MP and the SYP as well as in later parts of the summary of Z.4-11, Aristotle's interest shifts to the composite insofar as it has both a form and matter. As in Z.10, he argues that, if we consider the composite in that way, it should be defined with reference to both its form and its matter.

One might doubt, though, whether hierarchical purism can account for Aristotle's discussion of geometrical objects. I have argued that, in the MP, Aristotle objects to his opponents because they define geometrical objects with reference to their forms alone. Yet, on hierarchical purism, one might expect that Aristotle himself has to allow for such purely formal definitions of geometrical objects. For geometrical objects are intelligible composites, and the hierarchical purist holds that, in some contexts, composites should be defined with reference to their forms alone. But if that is right, why does Aristotle object to the purely formal definitions offered by his opponents?

In response, the hierarchical purist should urge the analogy between Aristotle's treatment of intelligible and sensible composites. First of all, there is some evidence in Z.10-11 that, even for geometrical objects, Aristotle sometimes calls for purely formal definitions. In Z.10, he excludes mention of the segments of the circle from the definition of the circle on the grounds that they are its parts 'as matter in which [the circle] comes to be' (1035a12). Since he also says that the segments in question are 'closer to the form than the bronze when roundness comes to be in bronze' (1035a13-14), Aristotle seems to exclude mention of the 
intelligible material parts from the definition of the mathematical circle. ${ }^{35}$ Similarly, in Z.11, he excludes mention of the semi-circles from the definition of the circle on the grounds that they are its intelligible material parts (1036b32-37a5). Hence, Aristotle does not seem to object to purely formal definitions of geometrical objects tout court.

Nonetheless, in the MP, Aristotle does object to such purely formal definitions, or so I have argued. The hierarchical purist can offer a resolution of the apparent conflict in line with her interpretation of Aristotle's treatment of sensible composites. The passage from Z.10 where Aristotle excludes mention of the segments from the definition of the circle occurs in the Hylomorphic Passage which leads into part [A] of the Puzzling Passage. In those passages, on the hierarchical purist interpretation, Aristotle discusses the composite only insofar as it has a form, and that is why he concludes for geometrical objects, no less than for sensible composites, that they ought to be defined with reference to their forms alone. Presumably, the same is true of the related passage in Z.11 (1036b32-37a5), although it is notoriously controversial what its exact place in the argument structure of Z.10-11 is. ${ }^{36}$

By contrast, in the MP, on the reading just offered, Aristotle is interested in geometrical objects insofar as they have both a form and (intelligible) matter. Hence, in the MP, but not in the other passages mentioned above, Aristotle concludes that one should mention intelligible matter in the definition of geometrical objects. His objection to the opponents is that they remove reference to intelligible matter no matter what. But in that case, removing mention of the matter

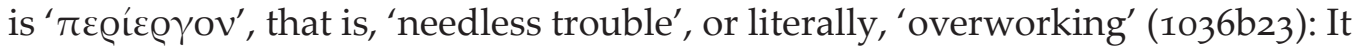
is not always the case that one should define composites, including both sensible and intelligible composites, with reference to their forms alone. As we will see shortly, in some contexts, it would be a mistake to omit reference to the matter of the composite.

That said, one can put a different spin on the objection, offering what we might call the no-context objection. In the MP, Aristotle does not appear to qualify the claim that geometrical objects should not be purely formally defined. Instead, he seems to condemn his opponents outright for their definitional practice. In fact, the same problem seems to arise from Aristotle's discussion of sensible composites. For instance, when Aristotle says that the animal should be defined with reference to its functional material parts in the SYP, his claim does not seem to be restricted to any particular context. In the summary of Z.4-11, too, Aristotle

35. On this topic, see also Section 2 above.

36. For a discussion, see Ps.-Alexander (515.6-11), Ross (1924: 203), Frede \& Patzig (1988: 214). Only Ross thinks that the passage originally belonged where it is now, while the other commentators treat it as a later insertion (according to Ps.-Alexander, Eudemus moved it from 1034b2435a17). 
appears to claim unqualifiedly that the only definition of a composite is in accordance with primary substance. The objection to hierarchical purism, then, is that it restricts Aristotle's claims to certain contexts, even though Aristotle himself does not explicitly restrict them in that way.

I will concede that Aristotle does not explicitly restrict his claims to any particular context. For instance, he does not come out and say that it is wrong only in some contexts to define geometrical objects purely formally. But I have argued above that there are markers which suggest implicit restrictions. On the hierarchical purist view, then, the explanation why Aristotle does not make the restrictions explicit is simply that, in the relevant passages, Aristotle is already operating within one or the other context. For example, in the SYP, Aristotle can put forward the claim that an animal should be defined with reference to its functional material parts without explicitly restricting that definitional practice to the context where one studies animals insofar as they have both a form and matter. For, in putting forward that claim, he is already operating in that context; and similarly for other passages.

If we grant the hierarchical purist all those moves, her burden becomes to elucidate what the different contexts are in which a composite should be considered and defined in one or the other way. Let us therefore turn to Aristotle's definitional claims in more detail.

\subsection{Two Definitions}

On hierarchical purism, each composite has two definitions, one in terms of its formal parts alone, and one in terms of both its formal and (some of) its material parts. That consequence of hierarchical purism becomes less surprising if we compare the view with Frede's version of hard purism. On Frede's (1990: 113-114) view, composites are defined with reference to their forms alone in first philosophy, but in Aristotle's natural philosophy, composites are defined with reference to both their form and their matter. Where the hierarchical purist differs from the hard purist is that he takes the definitional concerns of natural philosophy to feature in Zeta alongside the more austere definitional concerns of first philosophy.

There are some general considerations in favour of taking the definitional concerns of natural philosophy to be present in Zeta. The central question of Zeta, what primary substance is, is answered in terms of matter and form, apparently culminating in the conclusion that form is primary substance (Z.II, 1037a29). Indeed, Aristotle introduces the details of the matter-form distinction into Zeta by way of a précis of some results from the Physics in Z.7-9. ${ }^{37}$ It is hardly

37. Frede \& Patzig (1988: 104) take Z.7-9 to be a later addition by Aristotle, but even if that is right, they were surely added for a purpose, namely, in order to introduce the machinery of matter and form which is absent from Z.4-6 and which plays a crucial role in Z.10-11. 
shocking that he should import the definitional concerns of natural philosophy along with that technical machinery. Towards the end of Z.11, Aristotle even makes explicit that, in Z.10-11, the interests of physics have not been excluded, on the contrary, 'in a sense, the enquiry concerning perceptible substances is a function of physics and second philosophy' (1037a14-16).

But the main reason why we should acknowledge that, contra the hard purist, definitions in the style of natural philosophy have a place in Zeta is simply that, in Z.10-11, Aristotle prominently discusses how a composite should be defined if it is considered insofar as it has both a form and matter. For it is not the first philosopher but the physicist who is interested in the composite insofar as it has both a form and matter. In Metaphysics E.1, for example, we are told that 'physics is about separable but not unmovable things' (1026a13-14), and just like in the Socrates the Younger Passage (1036b29-30), Aristotle connects movability with (perceptible) matter to conclude concerning the definition given by the physicist: 'The account of none of [the natural things] is without motion, but it always has matter' (1026a2-3). ${ }^{38}$

Similarly, I submit, it is the definitional concerns of the physicist which are heeded when, in Z.10-11, Aristotle argues that the composite insofar as it has both a form and matter should be defined with reference to both its form and its matter. By contrast, when Aristotle argues that the composite insofar as it has only a form should be defined in purely formal terms, he is taking on the definitional concerns of first philosophy which abstracts away from the material features of matter-form composites.

However, the two definitions, the first-philosophical or metaphysical one and the second-philosophical or physical one, are not on equal footing. Indeed, strictly, only the metaphysical definition is a definition at all. For a definition is an account which states the essence of an object (Meta. Z.5, 1031a12), and the essence of a composite is its form (see Meta. Z.7, 1032b1-2; Z.10, 1035b14-16; Z.11, 1037a28-29). Hence, only the metaphysical definition states the essence of the composite, and only the metaphysical definition is a definition, strictly speaking. How does that outcome bear on the status of the physical definition?

In Section 1, I said that the accounts or $\lambda$ ó $\gamma o l$ with which Z.10-11 is concerned are definitions. However, I also noted that Aristotle does not always use definitional language in the strictest sense, for example, in speaking of 'defining' organs and geometrical objects (1035b7-11; 1036b8-10), which, as non-substances, are, strictly speaking, not definable. There is some evidence that matter-form composites do not turn out to be strictly definable either if one thinks about them

38. See also DA I.1, 403ab6-12 and Phys. II.2, 194a12-16. Frede \& Patzig (1988: 212) claim that not the account but the object to be defined has matter. But a parallel with Meta. Z.7, where Aristotle says that 'the bronze circle has matter in its account' (1033a5) suggests that, in E.1, too, it is the account which has matter. 
in the way the physicist does, namely, insofar as they have both a form and matter.

For in Metaphysics E.1, Aristotle says that 'all natural things are said like the snub' (1025b34-26a1), and proceeds to assign the study of such snub-like things to the physicist (1026a24-26). But in Z.5, Aristotle claims that coupled entities like the snub can be defined only in a loose sense of 'definition' (1031a5-11). Hence, the definitions offered by the physicist of composites in terms of both their form and matter are not definitions in the strictest sense (see Code 2010: 207-208). On the other hand, since the essence of a composite is its form, the purely formal definitions provided by the first philosopher are definitions in the strictest sense.

The two definitions of the composite, then, are hierarchically ordered: Strictly, only the metaphysical definition is a definition of the composite, but loosely, one can also speak of a physical 'definition' which mentions not just the form or essence of the composite. Of course, the physicist is also interested in the essence or form of the composite: 'For the physicist needs to gain knowledge not only of matter but also of the substance in accordance with the account, and more so' (Z.11, 1037a16-17). Still, the definitional project of the physicist aims at a 'whatit-is' of the composite which is broader than its essence or form: 'It is clear how one needs to search for the what-it-is ( $\tau$ ò $\tau \dot{\imath} \dot{\varepsilon} \sigma \tau \iota)$ and [how one needs to] define

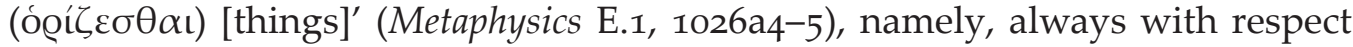
to their matter since the physical definition 'always has matter' (1026a3), as discussed above.

The hierarchical order, then, of the two definitions of the composite arises from their content. The metaphysical, purely formal definition is a definition in the strict sense because it mentions only the essence of the composite. The physical definition is, strictly speaking, not a definition because it states not the essence or form of the composite but its broader $\tau$ ' $\dot{\varepsilon} \sigma \tau \iota$ or 'what-it-is'. For Aristotle, that 'what-it-is' of the composite, stated in a physical definition, is not exhausted by its essence or form but comprises some of the material features of the composite, too. 39

Nonetheless, Aristotle speaks of the physical definition in definitional terms,

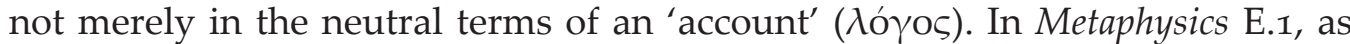
just seen, he says that the physicist's search for the 'what-it-is' of an object is an

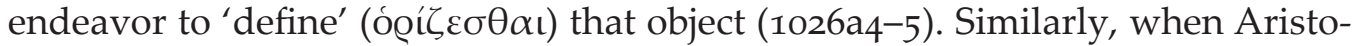
tle argues in the SYP that objects which are 'this-in-this' should be defined with reference to some of their material parts, he speaks of 'defining' (ógi $\zeta \varepsilon \sigma \theta \alpha \iota)$ the animal (1036b29), and he sets up his discussion as a response to a puzzle 'about definitions' (1036b21). The crucial point, then, is not that physical definitions

39. See Gill who draws a distinction between the essence and what she calls the 'nature' (1989: 114-116) or 'being' (2006: 356-359) of a composite. See also Code (2010: 205-206). 
cannot be called 'definitions' but rather that those definitions are not definitions in the strict sense because they do not state the essence but rather the broader 'what-it-is' of the composite.

Analogous considerations apply to intelligible composites. Above, I argued that, on the view developed in Z.10-11, intelligible composites, too, can be considered either only insofar as they have a form, or insofar as they have both a form and matter. In the former case, intelligible composites should be defined purely formally, in the latter case, they should be defined with reference to their intelligible matter as well. This is not the place to enter the difficult details of the relation between first philosophy and mathematics. ${ }^{\circ}$ But the picture in Z.10-11 suggests that, unlike geometry, first philosophy abstracts away from the intelligible material features of geometrical objects, just as it abstracts away from the perceptible material features of sensible objects. It is only in first philosophy, then, that one should consider and define composites just insofar as they have forms.

\subsection{Matter and Definition}

There is, however, the further question how there can be any definition of a composite which mentions both its form and its matter, even in a loose sense of 'definition'. In [B] of the Puzzling Passage, Aristotle discusses the definitions of particular composites in terms of the bits of matter into which they perish. Similarly, in the SYP, Aristotle seems to suggest that particular composites should be defined with reference to their concrete functional parts, such as the hand. $4^{11}$ But in Z.1o, Aristotle also claims that there is no definition of particulars (1036a2-9), and the reason he supplies is that 'matter by itself is not graspable (ä $\gamma v \omega \sigma \tau o \varsigma)$ ' (1036a8-9; see also Z.15, 1039b27-30). Aristotle's point is not that there is no definition of particulars at all. Rather, he claims that particulars 'are always said and grasped by the universal account' (1036a8). One strategy is to consider the composite only insofar as it has a form, and hence to define it in terms of its form alone (1035b34-16a1). But how can one define the composite, if one considers it insofar as it has both a form and matter?

I think that Aristotle recognizes that problem already in Z.10, and that it prompts him to introduce his notion of 'matter as universal' (Z.10, 1035b30; see Gill 1989: 135-136). Aristotle contrasts the matter of universal composites, that

40. For a discussion of the relation between first philosophy, second philosophy, and mathematics, see, e.g., Modrak (1989), and Lennox (2008).

41. Soft purists typically take the SYP to be concerned with universal composites (Gill 1989: 135-136; Ross 1924: 203). But in the Puzzling Passage, Aristotle was clearly concerned with particulars, and the talk of an 'ensouled' hand (1036b32) in the SYP suggests that Aristotle has in mind a concrete hand which, when dead, is no longer a hand, rather than a universal type of hand. 
is, species, with the concrete material parts of particulars, such as the flesh and bones of Socrates (1035b3o-31; see also Z.11, 1037a6-7). The relation between the matter of the particular composite and the matter of the universal composite can be understood as a relation of universalization: If one universalizes the particular bits of flesh and bones that make up Socrates one will end up with the flesh and bones 'as universal' of the human species.

Thus, although one cannot define a composite with reference to the particular bits of matter which make it up, one can define it with reference to its universalized matter, that is, the relevant kind of matter. For example, one can define Kallias insofar as he has both a soul and flesh and bones with reference to soul and the material kinds flesh and bones. The same solution can be applied to the concrete functional material parts mentioned in the SYP. It is the universalized functional parts which are mentioned in the definition of a composite. Moreover, even though Aristotle does not explicitly extend his account of universal composites to geometrical objects, a similar point might hold for intelligible matter. ${ }^{42}$ The spatial extension of a particular geometrical object cannot be mentioned in its definition, but the universalized extension, say, its dimensionality, is apt for being mentioned in the definition. There are, then, two ways of providing a universal account of particulars, either by mentioning only their forms, or by mentioning both their forms and their universalized material parts.

With respect to sensible composites insofar as they have both a form and matter, there is the further question whether their definitions mention the (universalized) material parts into which they perish or whether the definitions mention their (universalized) functional parts. We saw that Aristotle seems to claim the former in the Puzzling Passage but the latter in the SYP. As far as I can tell, Aristotle does not settle that question in Z.10-11. Still, given that Aristotle's prime example in Z.10-11 for matter into which animals perish, namely, flesh, turns out to be functional in the biological works (see, e.g., PA II.8, 653b19-25; GA II.1, 734b25-28), and that functional parts become more important over the course of Z.10-11, it seems that, ultimately, the (universalized) functional parts should be mentioned in the definition of the sensible composite.

Despite that last point, I think we should stop short of concluding with the reformist hard purists that, since ultimately only the functional parts of a sensible composite can be mentioned in its definition, none of its properly material parts will ever be mentioned. For Aristotle clearly speaks of the functional parts of a composite as its matter. For example, in arguing that the finger is posterior to the whole human being, he says that 'those things which are parts as matter and into which [the whole] is divided as into matter are posterior' (1035b11-12). Similarly, he urges later that the composite animal, unlike its soul, is divided

42. As anonymous referee $A$ has suggested. 
into the bodily parts 'as into matter' (1035b21). The functional parts of a composite are material no less than the parts into which the composite perishes.

\section{Purity}

I started out by characterizing our exegetical options in terms of the following two schematic claims which, in conjunction, suggest that, for Aristotle, forms are impure:

(1) The definition of a composite should mention only the form of the composite.

(2) The definition of a composite should mention the matter of the composite.

As I presented them, hard purists accept (1) and reject (2), while soft purists accept (2) and reject (1). We can now see why the hierarchical purist should reject both (1) and (2) as they stand but can accept qualified versions of both: The definition of a composite considered only insofar as it has a form should mention only the form of the composite. But the definition of the same composite considered insofar as it has both a form and matter should mention the (universalized) material parts of the composite as well.

How does that bear on the debate over the purity of forms? On hierarchical purism, all passages in Z.10-11 which the impurist took as evidence for the view that the matter of a composite is part of its form - where 'matter' was spelled out variously as '(functional) material parts' or 'material features' - are concerned with the composite insofar as it has both a form and matter. But if a composite is considered insofar as it has both a form and matter, it should be defined with reference to its non-formal material parts, and hence nothing follows from those passages for the purity of forms. By contrast, when Aristotle is interested in the composite only insofar as it has a form, he consistently maintains that the composite should be defined without reference to its matter. But if forms were impure, even if one considered the composite only insofar as it has a form, one would have to define it with reference to its matter, contrary to hierarchical purism. Thus, insofar as Metaphysics Z.10-11 supports hierarchical purism, the text also supports the view that, for Aristotle, forms are pure.

One advantage of that result is that there is no sign that the priority of form over matter might be undermined. For if forms are pure, no form is defined with reference to the matter of the composite to which it belongs, nor is the matter part of the essence of the form. It should be noted, however, just how abstract the discussion in Metaphysics Z.10-11 is. Even though examples of form and mat- 
ter are mentioned, those examples seem to be toy cases which await a thorough treatment elsewhere. But that division of labour raises the question whether the abstract framework developed in Metaphysics Z.10-11 will withstand the application to specific cases. In particular, one may wonder whether the definition of soul as, on one formulation, 'the first actuality of the natural body that has life potentially' (DA II.1, 412a27-28) does not imply the impurity of soul after all.

On the other hand, I think it would be a mistake to count the abstract nature of the discussion in Metaphysics Z.10-11 as a defect and to rely on the specifics of Aristotle's natural philosophy to correct the general conclusions reached in the Metaphysics. On the contrary, I am inclined to proceed the other way around: If Aristotle's metaphysical framework implies that forms are pure, our expectation should be that we can use that result to steer us towards a correct interpretation of applications of that framework. Hence, if hierarchical purism is the correct interpretation of Metaphysics Z.10-11, perhaps that interpretation can also help us understand less abstract Aristotelian texts, including De anima. But all that is a topic for future research.

\section{Acknowledgments}

I am immensely grateful to Mary Louise Gill, David Charles, Jacob Rosen, and Justin Broackes for our tireless discussions of Metaphysics Z.10-11. I would also like to thank Jonathan Beere, Emily Katz, Jeremy Kirby, Hendrik Lorenz, Benjamin Morison, and audiences at the Princeton Classical Philosophy Work in Progress Seminar and the Pacific APA, Vancouver for their stimulating questions. Finally, I have greatly profited from the detailed comments by two anonymous referees and the area editor for Ergo.

\section{References}

(Pseudo-)Alexander (1891). Alexandri Aphrodisiensis in Aristotelis Metaphysica Commentaria. Michael Hayduck (Ed.). G. Reimer. https://doi.org/10.1515/9783110807677

Bonitz, Hermann (1848-49). Aristotelis Metaphysica. A. Marcus.

Bostock, David (1994). Aristotle Metaphysics Books Z and H. Clarendon Press.

Caston, Victor (2008). Commentary on Charles. Proceedings of the Boston Area Colloquium of Ancient Philosophy, 24(1), 30-49.

Charles, David (2008). Aristotle's Psychological Theory. Proceedings of the Boston Area Colloquium of Ancient Philosophy, 24(1), 1-29.

Charles, David (2009). Aristotle on Desire and Action. In Dorothea Frede and Burkhard Reis (Eds.), Body and Soul in Ancient Philosophy (291-308). De Gruyter. https://doi.org/10.1515/9783110216523.3.291

Chiaradonna, Riccardo (2014). La chair et le bronze. Remarques sur Métaphysique Z, I1 et l'interprétation de M. Frede et G. Patzig. Les Études philosophiques, 110(3), 375-388. https://doi.org/10.3917/leph.143.0375 
Code, Alan (2010). Commentary on Devereux. Proceedings of the Boston Area Colloquium of Ancient Philosophy, 26(1), 197-209.

Devereux, Daniel (2010). Aristotle on the Form and Definition of a Human Being: Definitions and Their Parts in Metaphysics Z.10 and 11. Proceedings of the Boston Area Colloquium of Ancient Philosophy, 26(1), 167-96. https://doi.org/10.1163/22134417-90000125

Ferejohn, Michael (1994). The Definition of Generated Composites in Aristotle's Metaphysics. In Theodore Scaltsas, David Charles, and Mary Louise Gill (Eds.), Unity, Identity, and Explanation in Aristotle's Metaphysics (291-318). Oxford University Press.

Frede, Michael (1990). The Definition of Sensible Substances in Met. Z. In Daniel Devereux and Pierre Pellegrin (Eds.), Biologie, Logique et Métaphysique chez Aristote (113129). Éditions du centre national de la recherche scientifique.

Frede, Michael and Günther Patzig (1988). Aristoteles "Metaphysik Z" (Vol. 2). Beck.

Furth, Montgomery (1985). Aristotle Metaphysics Books VII-X. Hackett.

Gill, Mary Louise (1989). Aristotle on Substance. Princeton University Press.

Gill, Mary Louise (2006). First Philosophy in Aristotle. In Mary Louise and Pierre Pellegrin (Eds.), A Companion to Ancient Philosophy (347-373). Blackwell. https://doi. org/10.1002/9781444305845.ch18

Heinaman, Robert (1997). Frede and Patzig on Definition in Metaphysics Z.10-11. Phronesis, 42(3), 283-298. https://doi.org/10.1163/15685289760518171

Irwin, Terence (1988). Aristotle's First Principles. Oxford University Press.

Kapp, Ernst (1923). Sokrates der Jüngere. Philologus, 79(3), 225-233. https://doi. org/10.1515/phil-1923-0302

Lennox, James G. (2008). "As If We Were Investigating Snubness": Aristotle on the Prospects for a Single Science of Nature. Oxford Studies in Ancient Philosophy, 35, 149-186.

Malink, Marko (2013). Essence and Being. Oxford Studies in Ancient Philosophy, 45(1), 341362. https://doi.org/10.1093/acprof:oso/9780199679430.003.0010

Menn, Stephen (2001). Metaphysics Z 10-16 and the Argument-Structure of Metaphysics Z. Oxford Studies in Ancient Philosophy, 21, 83-134.

Modrak, Deborah K. W. (1989). Aristotle on the Difference between Mathematics and Physics and First Philosophy. Apeiron, 22(4), 121-139. https://doi.org/10.1515/ apeiron.1989.22.4.121

Morrison, Donald (1990). Some Remarks on Definition in Metaphysics Z. In Daniel Devereux and Pierre Pellegrin (Eds.), Biologie, Logique et Métaphysique chez Aristote (131144), Éditions du centre national de la recherche scientifique.

Mueller, Ian (1970). Aristotle on Geometrical Objects. Archiv für Geschichte der Philosophie, 52(2), 156-171. https://doi.org/10.1515/agph.1970.52.2.156

Peramatzis, Michail (2011). Priority in Aristotle. Oxford University Press.

Peramatzis, Michail (2015). What Is a Form in Aristotle's Hylomorphism? History of Philosophy Quarterly, 32(3), 194-216.

Ross, William D. (1924). Aristotle's Metaphysics (Vol. 2). Clarendon Press.

Wedin, Michael (2000). Aristotle's Theory of Substance. Oxford University Press.

Whiting, Jennifer (1986). Form and Individuation in Aristotle. History of Philosophy Quarterly, 3(4), 359-377.

Whiting, Jennifer (1991). Meta-Substance: Critical Notice of Frede-Patzig and Furth. The Philosophical Review, 10o(4), 607-639. https://doi.org/10.2307/2185176 